\title{
New tumor-targeted nanosized delivery carrier for oligonucleotides: characteristics in vitro and in vivo
}

This article was published in the following Dove Press journal:

International Journal of Nanomedicine

2I July 20I I

Number of times this article has been viewed

\author{
Tianyang Zhou ${ }^{1,2}$ \\ Xin Jia' \\ Huixiang $\mathrm{Li}^{3}$ \\ Jin Wang ${ }^{3}$ \\ Hongling Zhang ${ }^{1,2}$ \\ Youmei $A^{1,2}$ \\ Zhenzhong Zhang ${ }^{1,2}$
}

'School of Pharmaceutical Sciences, ${ }^{2}$ Nanotechnology Research Center for Drugs, ${ }^{3}$ Department of Pathology, Medical School of Zhengzhou

University, Zhengzhou,

People's Republic of China
Correspondence: Zhenzhong Zhang Nanotechnology Research Center for Drugs, Medical School of Zhengzhou University, Zhengzhou 45000 I, People's Republic of China Tel $+8637 \mid 67781910$

Fax +8637167781908

Email zhangzz08@126.com
Background: The purpose of this study was to investigate the in vitro and in vivo characteristics of a new tumor-targeted nanosized delivery carrier for antisense oligonucleotide (ASON).

Methods: Polyethylenimine (PEI) was used to condense ASON to form nanosized complexes (PEI/ASON), which were then modified using asparagine-glycine-arginine (NGR) peptide to obtain a tumor-targeted nanosized delivery carrier (NGR/PEI/ASON). The conditions required to form PEI/ASON were investigated.

Results: A linear correlation between the natural logarithm of the N/P ratio (PEI to ASON) and the zeta potential of the PEI/ASON complexes was found, ranging from 1.5 to 5.0. The $\mathrm{pH}$ of the solution strongly influenced the zeta potential of the PEI/ASON complexes. PEI/ASON and NGR/PEI/ASON were stable in RPMI-1640 culture medium in the presence of Dextran 70. Incorporation of ASON into PEI/ASON and NGR/PEI/ASON complexes prevented degradation of ASON by DNase I.

Conclusion: Both ASON/PEI and NGR/PEI/ASON complexes enhanced the uptake of ASON by EC9706 cells in vitro. In vivo, NGR/PEI/ASON complexes had the ability to target tumor tissues effectively.

Keywords: nanosized delivery system, squamous cell carcinoma, antisense oligonucleotide

\section{Introduction}

Treating tumors using targeting genes could halt tumor progression without toxicity to normal cells. Therefore, gene therapy is considered a promising therapeutic strategy for malignant tumors and genetic diseases, and has been studied worldwide for the past two decades. ${ }^{1}$ Antisense oligonucleotide (ASON) to inhibit mRNA expression has been studied as a potentially important gene therapy in recent years., ${ }^{2,3}$

$\mathrm{ASONs}^{4,5}$ have shown promising results as agents for specific manipulation of genes to inhibit gene expression in vitro and in vivo. However, the development of antisense therapeutics has been frustrated by poor bioavailability as a result of degradation of DNA by nucleases and insufficient affinity for target cells. ${ }^{6}$

Although viral gene carriers are highly effective, their fundamental shortcomings, such as toxicity, limited capacity to carry DNA, potential for virus recombination, and high cost, limit their practical application in gene therapy. Therefore, researchers have recently paid more attention to nonviral carriers with the characteristics of safety, low cost, easy modification, and lack of immunogenicity and mutagenesis. ${ }^{7,8}$ However, traditional nonviral gene carriers, such as bare DNA, liposome or cationic polymers, and cationic lipids, have low transfer efficacy. ${ }^{9}$ 
Polyethylenimine (PEI) is one of the most efficient nontargeted polycations used for gene delivery. PEI and its derivatives are generally known to be effective dispersants and cationic flocculants, and are believed to interact with negatively charged colloids. PEI, with its high positive charge density in aqueous solution, has recently been considered as a promising candidate for delivery of negatively charged DNA molecules. The relatively high efficacy of PEI is believed to stem from its high amine density and buffering capacity. PEI forms complexes with DNA as a result of electrostatic interactions between the ammonium groups of PEI and the phosphate groups of DNA. ${ }^{10}$

Traditional approaches to cancer therapy have focused on targeting and destroying cancer cells. ${ }^{11}$ However, direct access to cancer cells is often restricted, leading to limited success of various agents, including DNA and RNA. To overcome this barrier, recent strategies have attempted to target the tumor vasculature instead of the cancer cells. Suppression of new blood vessel formation (anti-angiogenic therapy) and destruction of established tumor vasculature (antivascular therapy) have both been explored. Lack of a functional vasculature leads to tumor starvation and eventually to tumor regression. Thus, drug therapy targeted to the tumor vasculature has emerged as one of the most promising approaches for the treatment of cancer.

Endothelial cells in the angiogenic vessels within solid tumors express several proteins that are absent or barely detectable in other blood vessels, ${ }^{12}$ including integrin $\alpha_{\mathrm{v}} \beta_{3}$ and $\alpha_{\mathrm{v}} \beta_{5}$, aminopeptidase, vascular endothelial growth factor receptor, matrix metalloproteinase, proteoglycan, and prostate-specific membrane antigen. Some of these are already used as targets for tumor-specific delivery of therapeutic agents. Among the various new targeting ligands identified, peptides containing the asparagine-glycinearginine (NGR) motif have been shown to home into tumors by binding to CD13. Although there are several subpopulations of CD13, which are relatively widely distributed in the body, only one isoform is believed to be the receptor for NGR peptide. This isoform has been shown to be expressed exclusively in the neovasculature of tumor tissue. Ever since the discovery of NGR tumor-homing peptide ligand, researchers have used this ligand as a target for the delivery of various antitumor compounds, including chemotherapeutic drugs, apoptotic peptides, viral particles, and cytokines. NGR peptide targets tumor vessels by binding to the CD13-specific isoform. ${ }^{13,14}$

A new strategy for the condensation of ASON was developed in this study to generate a tumor-targeted delivery system for ASON. PEI were used to condense ASON into nanoscale PEI/ASON complexes modified with NGR peptide (NGR/PEI/ASON). The preparation conditions, including $\mathrm{N} / \mathrm{P}$ ratio, buffer solution, ASON concentration, and $\mathrm{pH}$, were optimized in the study. The characteristics of PEI/ ASON and NGR/PEI/ASON complexes were investigated in an esophageal carcinoma cell line and an established esophageal carcinoma model in nude mice.

\section{Methods and materials \\ Materials}

hTERT ASON, 5'-CCGCCCTCTCCTCGCGGCGCGAGTT-3' complementary to the hTERT gene promoter region (AF128893) was generated, and the nonsense oligodeoxynucleotide, 5'-GAGCATTAGCACCGCGGGC-3', was used as a negative control in vitro and in vivo. Both of the oligodeoxynucleotides were synthesized by SBS Genetech (Beijing, China).

PEI with a molecular weight of $25 \mathrm{kDm}$ and 4-(2-hydroxyethyl)-1-piperazine ethanesulfonic acid (Hepes) was purchased from Sigma Corporation (St Louis, MO). NGR peptide $\left(\mathrm{CNGRCK}_{2} \mathrm{HK}_{3} \mathrm{HK}_{11}\right.$ ) with or without FAM was synthesized by GL Biochem Co Ltd (Shanghai, China), with $\mathrm{C}$ being cysteine, $\mathrm{N}$ being asparagine, $\mathrm{G}$ being glycine, $\mathrm{R}$ being arginine, $\mathrm{H}$ being histidine, and $\mathrm{K}$ being lysine. L-1-tosylamido-2-phenylethyl chloromethyl ketone (TPC)trypsin, RPMI-1640 culture medium, and fetal bovine serum were obtained from Gibco (Carlsbad, CA). Dextran-70 and PEG-6000 were obtained from Amersham Biosciences AB (Uppsala, Sweden). Pluronic F-68 was purchased from Fluke Corporation (Everett, WA).

\section{Instruments}

A zetasizer (Nano ZS90; Malvern, Worcestershire, UK), atomic force microscope (SPM-9500J3; Shimadzu, Tokyo, Japan), confocal fluorescence microscope (Zeiss, Oberkochen, Germany), cell flow cytometer (Partec Company, Munich, Germany), and a thin-layer gel optical scanning system (Gene Genius, Syngene, Frederick, MD) were used in this study.

\section{Cell line and animals}

The esophageal carcinoma cell line (EC9706) was gifted by the National Laboratory of Molecular Oncology, Chinese Academy of Medical Sciences, Beijing, China. The cells were maintained in RPMI-1640 medium supplemented with $10 \%$ fetal bovine serum, penicillin $100 \mathrm{IU} / \mathrm{mL}$, and 100 streptomycin IU/mL. The cultures were incubated at $37^{\circ} \mathrm{C}$ in a humidified atmosphere containing $5 \% \mathrm{CO}_{2}$. Female BALB/C 
nude mice (4-6 weeks of age) were purchased from the Institute of Laboratory Animal Science, Chinese Academy of Medical Sciences, Beijing, China, and housed in the pathogen-free animal facility at the Animal Laboratory Center of Zhengzhou University. For the esophageal carcinoma model, EC9706 cells were trypsinized, washed twice with phosphate-buffered saline, and injected into the mice subcutaneously as $2 \times 10^{6}$ cells into the axillae bilaterally.

\section{PEI/ASON and NGR/PEI/ASON complexes}

The PEI/ASON complexes were prepared in 1\% Dextran solution with $5 \%$ glucose at various ratios of PEI nitrogen to ASON phosphate (N/P ratio) under different $\mathrm{pH}$ conditions. Different amounts of ASON were dissolved, and PEI solution was then transferred into these ASON solutions. The solutions were vortexed for 20 seconds and left at room temperature for 30 minutes. The procedure followed for preparation of the NGR/PEI/ASON complexes was the same as for the PEI/ASON complexes, except that NGR peptide solution was added to the ASON solutions.

\section{Size and zeta potential analysis}

The PEI/ASON and NGR/PEI/ASON complexes were suspended in deionized water at a concentration of $1 \mathrm{mg} / \mathrm{mL}$ to measure their sizes and zeta potentials using the Nano ZS90.

\section{Image observation}

A $15 \mu \mathrm{L}$ quantity of each complex solution was dropped onto a freshly prepared mica surface to dry at room temperature. Images of the PEI/ASON or NGR/PEI/ASON complexes were then captured by atomic force microscopy.

\section{Ability of PEI to condense ASON}

To determine the ability of PEI to condense ASON, increasing amounts of PEI were added to a fixed amount $(100 \mu \mathrm{g} / \mathrm{mL})$ of ASON at N/P ratios of $3: 0,3.5,4.0,4.5$, 5.0, 6.0, 7.0, 8.0, and 9.0. The complex solutions were centrifuged at 12,000 rpm for 10 minutes (HERMLE Z232) and then allowed to stand for 1 hour at $4^{\circ} \mathrm{C}$. Samples of supernatant $(5 \mu \mathrm{L})$ were loaded onto $1.2 \%$ agarose gel in Tris-acetate-EDTA buffer and visualized using an ultraviolet transilluminator.

\section{Protection of ASON against DNase I degradation}

The ability of the PEI/ASON complexes to withstand DNase I degradation was evaluated. PEI/ASON complexes were prepared at an N/P ratio of 4.0 or 10.0 using a final ASON concentration of $100 \mu \mathrm{g} / \mathrm{mL}$. The complexes $(17 \mu \mathrm{L})$, as well as a control solution of ASON, were incubated with DNase I $1 \mu \mathrm{L}$ in the presence of $5 \mathrm{mM} \mathrm{MgCl}$ at $37^{\circ} \mathrm{C}$ for 1 hour. Degradation was stopped by addition of EDTA (final concentration $0.05 \mathrm{M}$ ). Samples were loaded onto $1.2 \%$ agarose gel and visualized using an ultraviolet transilluminator.

\section{Uptake of PEI/ASON complexes by EC9706 cells}

The in vitro transfection efficacy of PEI/ASON or NGR/PEI/ ASON complexes was evaluated in the EC9706 cell line. Cells were seeded in six-well plates at a density of $1 \times 10^{6 /}$ well and maintained in RPMI-1640 medium supplemented with $10 \%$ fetal bovine serum, streptomycin $100 \mathrm{IU} / \mathrm{mL}$, penicillin $100 \mathrm{IU} / \mathrm{mL}$, and $4 \mathrm{mM}$ L-glutamine at $37^{\circ} \mathrm{C}$ in a humidified 5\% $\mathrm{CO}_{2}$ incubator. During transfection, FAMlabeled ASON $\left(\mathrm{C}_{\mathrm{ASON}}=100 \mu \mathrm{g} / \mathrm{mL}\right)$ complexes $(\mathrm{PEI} / \mathrm{ASON}$ and NGR/PEI/ASON) were added to the EC9706 cells in RPMI-1640 medium and incubated for 1.5 hours at $37^{\circ} \mathrm{C}$. Following incubation, the cells were washed with phosphatebuffered saline and fixed with cold ethanol for 30 minutes. The cells were observed by confocal fluorescence microscopy.

In vivo distribution of PEI/ASON or NGR/PEI/ASON The mice used in this study were inoculated with $1 \times 10^{7}$ EC9706 tumor cells in the dorsal flank, and the tumors were allowed to grow to a diameter of $0.8-1.0 \mathrm{~cm}$. The mice were maintained using a standard diet, bedding, and environment, with free access to food and drinking water. Six mice with the human esophageal cancer xenografts were randomly divided into two groups and injected with NGR/PEI/ASON or PEI/ASON complexes through the tail vein.

At hours 1, 3, and 6 after injection, the mice were sacrificed by cervical dislocation. The mice were then dissected, and the tissues of interest (liver, spleen, lung, kidney, and tumor) were collected immediately and frozen in powdered dry ice for 30 minutes. The prepared specimens were embedded in tissue optimum cutting temperature-freeze medium and refrozen for cryostat sectioning (3-5 $\mu \mathrm{m}$ in thickness). All tissue samples were observed by confocal fluorescence microscopy.

\section{Results and discussion Effects of N/P ratio on size and zeta potential of PEI/ASON complexes}

As seen in Figure 1, the sizes of the PEI/ASON complexes were about $120 \mathrm{~nm}$ at $\mathrm{N} / \mathrm{P}$ ratios of $1.5,2.0,4.0,6.0,8.0$, and 10.0. However, complexes with $\mathrm{N} / \mathrm{P}$ ratios of 0.5 and 1.0 


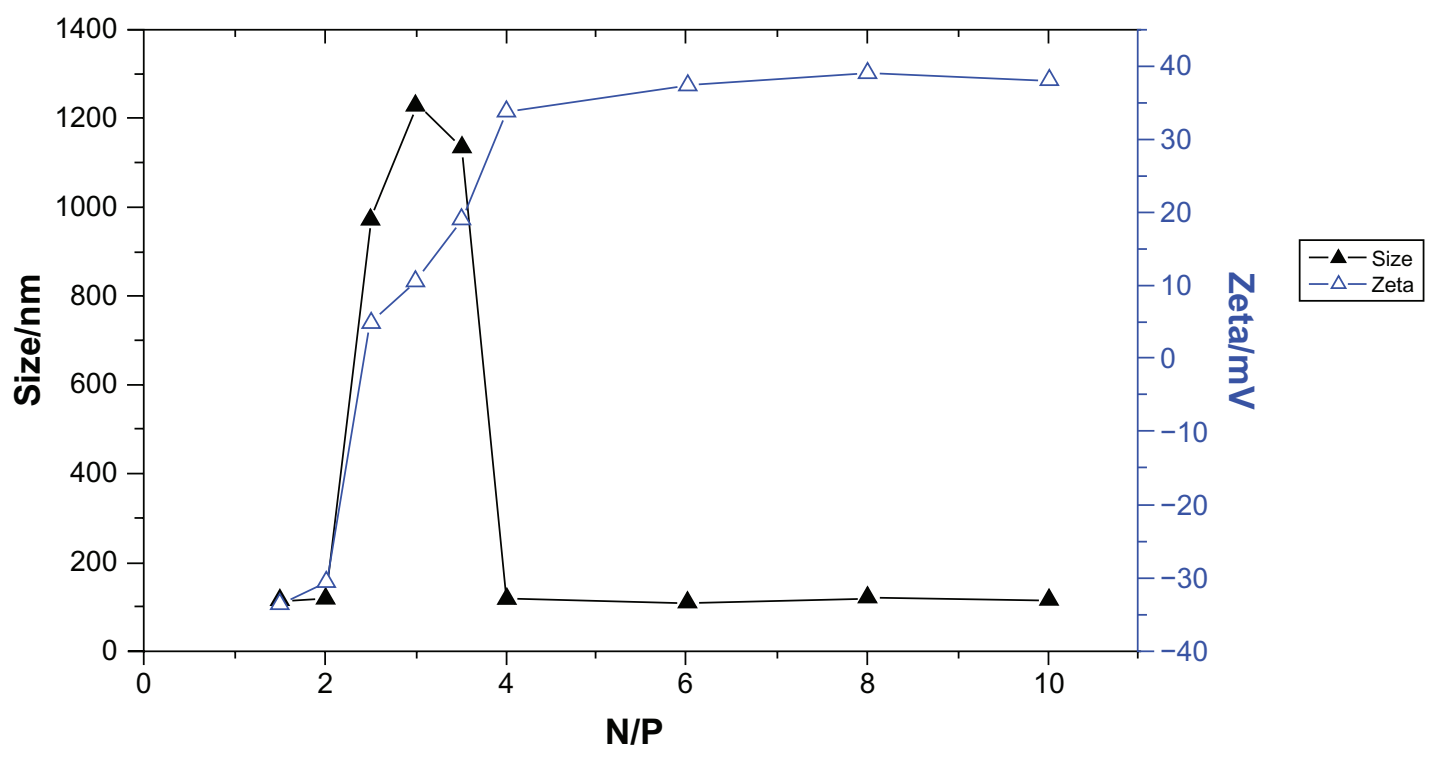

Figure I Effects of N/P ratio on size and zeta potential of PEI/ASON complexes. Abbreviations: PEI, polyethylenimine; ASON, antisense oligonucleotide.

were flocculated. At N/P ratios of 2.5, 3.0, and 3.5, the sizes of PEI/ASON complexes with a low zeta potential $(<20 \mathrm{mV})$ became large (about $1 \mu \mathrm{m}$ ), suggesting that these PEI/ASON complexes flocculated due to low zeta potentials.

The zeta potential of a gene delivery system is known to be one of the major factors influencing its transfection efficacy, ${ }^{15}$ and the zeta potential of PEI/ASON complexes appeared to increase with the N/P ratio, ranging from 1.5 to 10. As indicated in Figure 1, the zeta potential increased rapidly according to N/P ratio from 1.5 to 4 , but remained relatively stable at an N/P ratio of 4 to 10 .

The relationship between the N/P ratio and the zeta potential of the PEI/ASON complexes was investigated by stepwise regression analysis $(\alpha=0.01)$, and this indicated an obvious correlation between the natural logarithm of the $\mathrm{N} / \mathrm{P}$ ratio in the range of 1.5 to 5.0 and the zeta potential, with a linear regression equation of $\mathrm{Y}=-63.486+65.988 \mathrm{X}$ ( $\mathrm{X}$ and $\mathrm{Y}$ represented as the natural logarithm of N/P ratio and zeta potential, respectively, $r^{2}=0.9348$ ).

\section{Effects of $\mathrm{pH}$ on size and zeta potential of PEI/ASON complexes}

$\mathrm{PEI} / \mathrm{ASON}$ complexes with an N/P ratio of 4.0 were prepared to test the effect of $\mathrm{pH}$ on size and zeta potential. The results indicated that the size of the complexes was about $100 \mathrm{~nm}$ at a $\mathrm{pH}$ of 6.5 to 7.5. However, the size increased dramatically to $700 \mathrm{~nm}$ at a $\mathrm{pH}$ beyond 8.0. No significant change in zeta potential was observed at a $\mathrm{pH}$ below 7.5 , but this decreased dramatically at $\mathrm{pHs}$ in the range of 7.5 to 9.0 (Figure 2). These results suggest that $\mathrm{pH}$ strongly influences the zeta potential of PEI/ASON complexes and that the zeta potential is of importance for PEI/ASON complexes to remain stable in solution.

\section{Effects of polymers on size, zeta potential, and stability of complexes}

We evaluated the effects of different polymers, including Dextran 70, Pluronic F-68, and PEG-6000, on the aggregation of PEI/ASON complexes in the presence of RPMI-1640 culture medium. PEI/ASON complexes at an N/P ratio of 4.0 was stable in the presence of Dextran 70. Table 1 shows the protective effect of Dextran 70 on the PEI/ASON complexes at different concentrations in RPMI-1640 culture medium. However, Pluronic F-68 and PEG-6000 did not prevent aggregation of the PEI/ASON complexes in RPMI1640 culture medium (data not shown).

The effectiveness of Dextran 70 in stabilizing the PEI/ ASON complex could been explained by its dual hydrophobic-

Table I Protective effectiveness of Dextran-70 on PEI/ASON complexes at different concentration

\begin{tabular}{lllllll}
\hline Dextran-70 (\%) & $\mathbf{0}$ & $\mathbf{I}$ & $\mathbf{2}$ & $\mathbf{3}$ & $\mathbf{4}$ & $\mathbf{5}$ \\
\hline Size $(\mathrm{nm})$ & 1 & $194.2 \pm 11.3$ & $264.4 \pm 13.2$ & $303.2 \pm 18.7$ & $275.1 \pm 20.13$ & $363.4 \pm 34.9$ \\
\hline
\end{tabular}

Note: /, Complexes aggregation. 


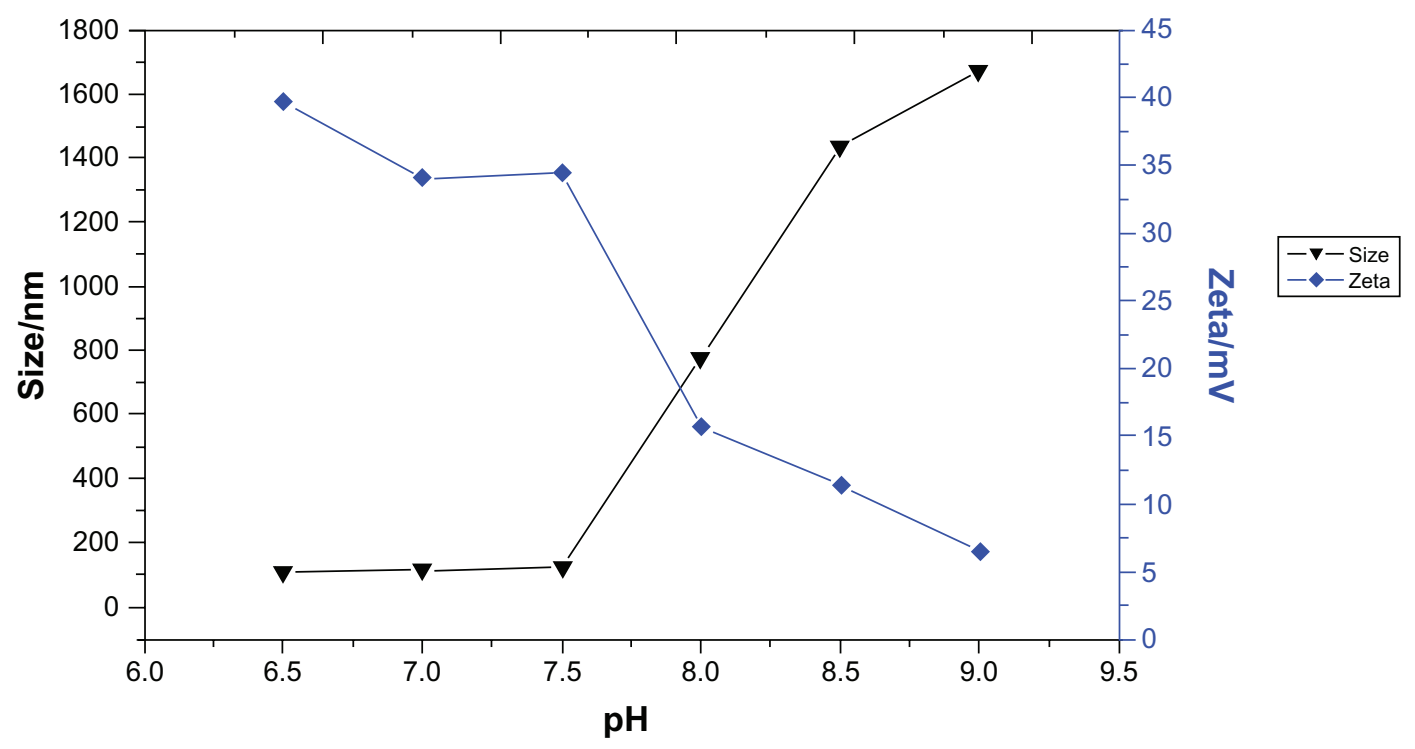

Figure 2 Effects of $\mathrm{pH}$ on size and zeta potential of PEI/ASON complexes.

Abbreviations: $\mathrm{PEI}$, polyethylenimine; ASON, antisense oligonucleotide.

hydrophilic nature, ${ }^{16}$ whereby the long hydrophilic chain of the surfactant prevents the complexes from coming into contact with each other, while the hydrophobic tail interacts with the hydrophobic portion of the PEI/ASON complex.

\section{Ability of PEI to condense ASON}

Electrophoresis on agarose gel was used to investigate the ability of PEI to condense ASON into PEI/ASON complexes. PEI was able to condense ASON into PEI/ASON complexes completely at an $\mathrm{N} / \mathrm{P}$ ratio $\geq 6.0$ (Figure 3 ). However, a free ASON band occurred at an N/P ratio $\geq 5.0$, indicating that PEI could not condense ASON completely at higher $\mathrm{N} / \mathrm{P}$ ratios.

\section{Protection against DNase I degradation}

As can be seen in Figures 4 and 5, naked ASON was degraded within 1 hour of incubation with DNase I. As

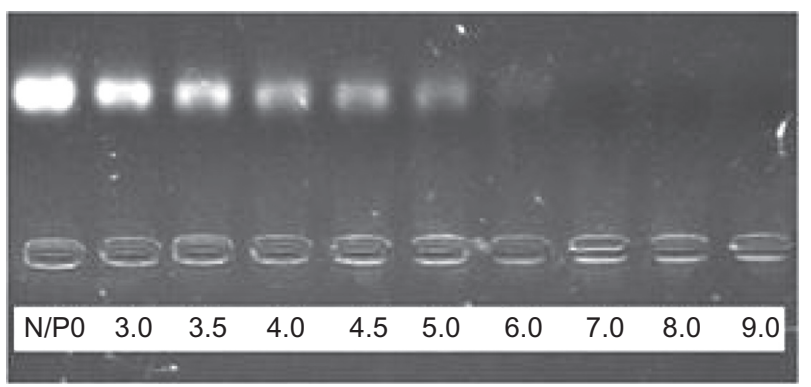

Figure 3 Agarose gel electrophoresis of PEI/ASON complexes at different N/P ratios.

Abbreviations: PEl, polyethylenimine; ASON, antisense oligonucleotide. expected, incorporation of ASON into the complexes inhibited the activity of DNase I. Both PEI/ASON and NGR/PEI/ASON complexes protected ASON to the same extent, regardless of N/P ratio (4.0 or 10.0). This could be explained by the fact that DNase I was unable to access the entrapped ASON.

The samples of ASON (1), PEI/ASON (N/P 4.0) (3) and PEI/ASON (N/P 10.0) (5) complexes were not degraded by DNase I. The samples of ASON (2), PEI/ASON (N/P 4.0) (4) and PEI/ASON (N/P 10.0) (6) complexes were degraded by DNase I (Figure 4).

The samples of ASON (1), NGR/PEI/ASON (N/P 4.0) (3) and NGR/PEI/ASON (N/P 10.0) (5) complexes were not degraded by DNase I. The samples of ASON (2), NGR/PEI/ASON (N/P 4.0) (4) and NGR/PEI/ASON (N/P 10.0) (6) complexes were not degraded by DNase I (Figure 5).

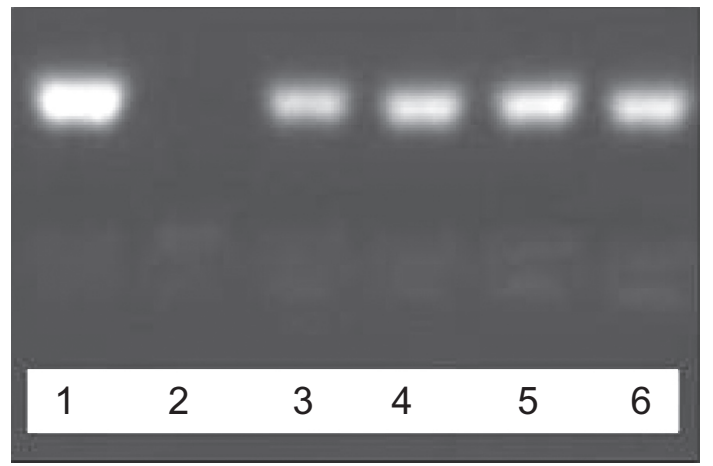

Figure 4 Agarose gel electrophoresis of PEI/ASON complexes. Abbreviations: $\mathrm{PEI}$, polyethylenimine; ASON, antisense oligonucleotide. 


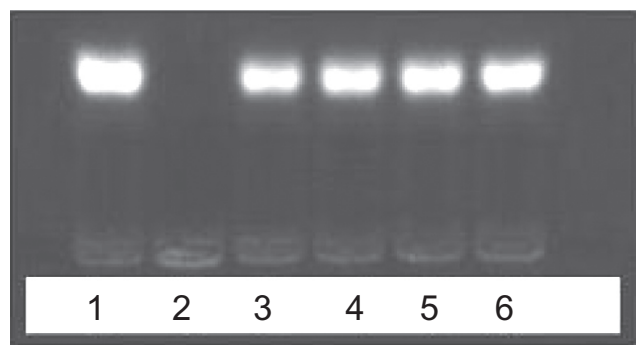

Figure 5 Agarose gel electrophoresis of NGR/PEI/ASON complexes.

Abbreviations: PEI, polyethylenimine; ASON, antisense oligonucleotide; NGR, asparagine-glycine-arginine peptide.

\section{Image of PEI/ASON and NGR/PEI/ASON complexes}

The images showed that the PEI/ASON and NGR/PEI/ASON complexes were of a uniform, smooth-surfaced, and spherical shape (Figure 6).

\section{Cellular uptake of PEI/ASON and NGR/PEI/ASON}

FAM-labeled ASON was used to evaluate cellular uptake of the PEI/ASON and NGR/PEI/ASON complexes. Human esophageal cancer EC9706 cells were treated with naked
ASON, PEI/ASON, and NGR/PEI/ASON complexes, and their cellular uptake was observed by confocal fluorescence microscopy. The intracellular fluorescence intensity in EC9706 cells treated with PEI/ASON or NGR/PEI/ASON complexes was stronger than that in EC9706 cells treated with naked ASON at 24 hours after treatment, indicating that the ASON/PEI and NGR/PEI/ASON complexes enhanced uptake of ASON by the EC9706 cells. However, no obvious differences between the groups of ASON/PEI and NGR/PEI/ ASON complexes were found (Figure 7).

\section{PEI/ASON and NGR/PEI/ASON biodistribution in tumor-bearing mice}

Liver, kidney, lung, heart, brain, and tumor tissues were removed from the mice to prepare frozen sections at hours 1,3 , and 6 after injection of the NGR/PEI/ASON or PEI/ ASON complexes. All samples were then observed by confocal fluorescence microscopy. Fluorescence intensity was strongest in the kidney and liver, followed by the lung and tumor tissue, and increased in these organs from 1-6 hours (Figure 8), indicating that the NGR/PEI/ASON complexes had a half-life of at least 6 hours. None of the other organs
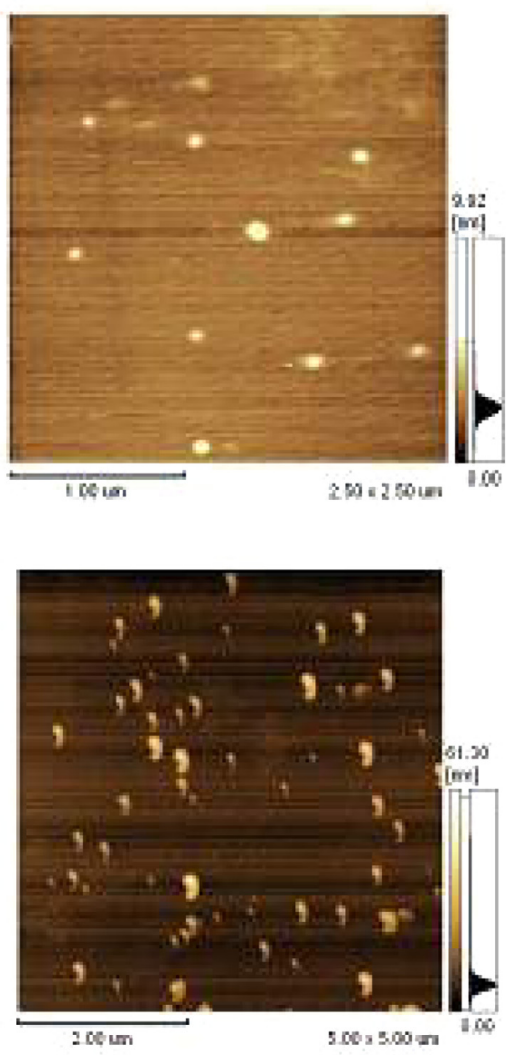
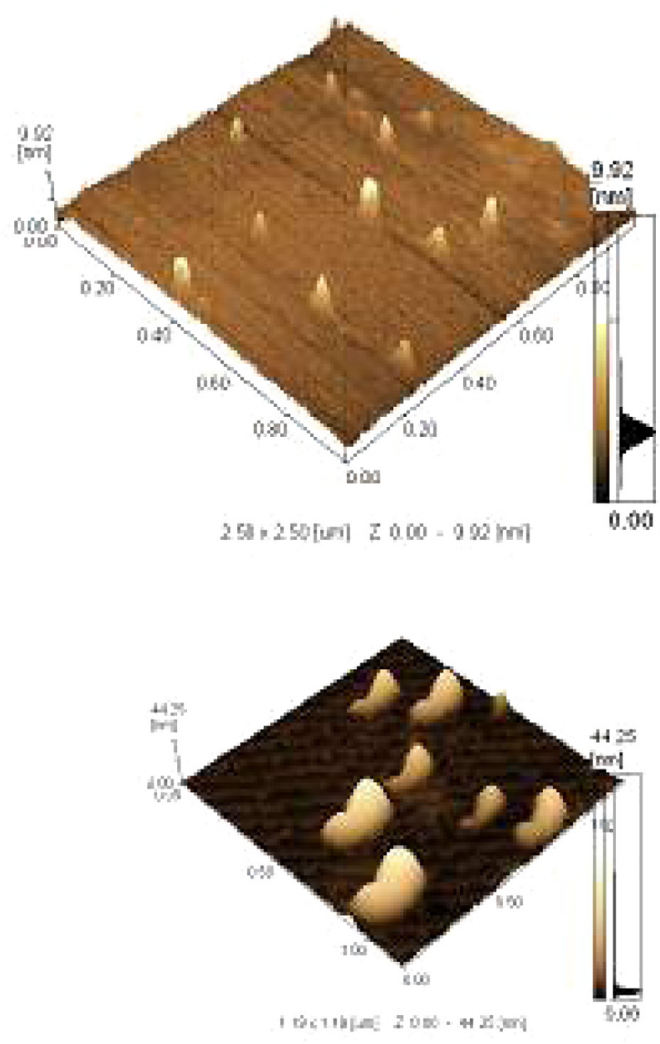

Figure 6 Upper PEI/ASON complexes; Lower NGR/PEI/ASON complexes.

Abbreviations: PEI, polyethylenimine; ASON, antisense oligonucleotide; NGR, asparagine-glycine-arginine peptide. 

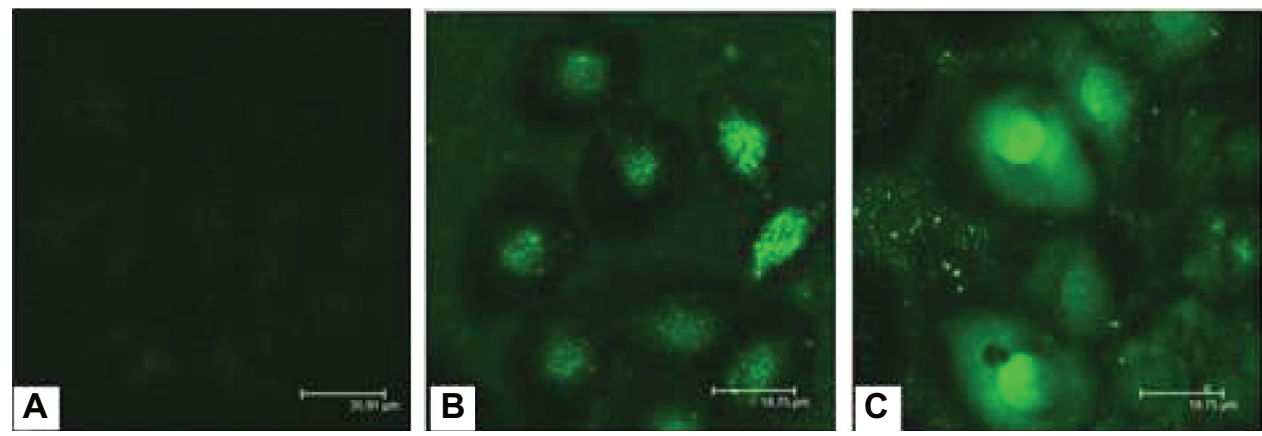

Figure 7 Fluorescent intensity in EC9706 cells observed by confocal fluorescence microscope. (A) ASON, (B) PEI/ASON, (C) NGR/PEI/ASON. Abbreviations: PEl, polyethylenimine; ASON, antisense oligonucleotide; NGR, asparagine-glycine-arginine peptide.

or tissues of mice injected with FAM-labeled ASON showed strong fluorescent intensity. High fluorescence accumulation in the kidney indicated that ASON was cleared primarily by the renal route.

Biodistribution of the PEI/ASON complexes was similar to that of the NGR/PEI/ASON complexes, except for their uptake in tumor cells. Tumor uptake increased gradually from 1-6 hours after injection of the NGR/PEI/ASON complexes, but this trend was not evident after injection of the $\mathrm{PEI} / \mathrm{ASON}$ complexes. In comparison with the fluorescent tumor intensity in the mice injected with the NGR/PEI/ASON complexes, the fluorescent intensity in the tumors of mice injected with PEI/ASON was significantly lower, suggesting that the NGR peptide may enhance the ability of an ASON delivery system to home to tumor tissues. NGR peptide or

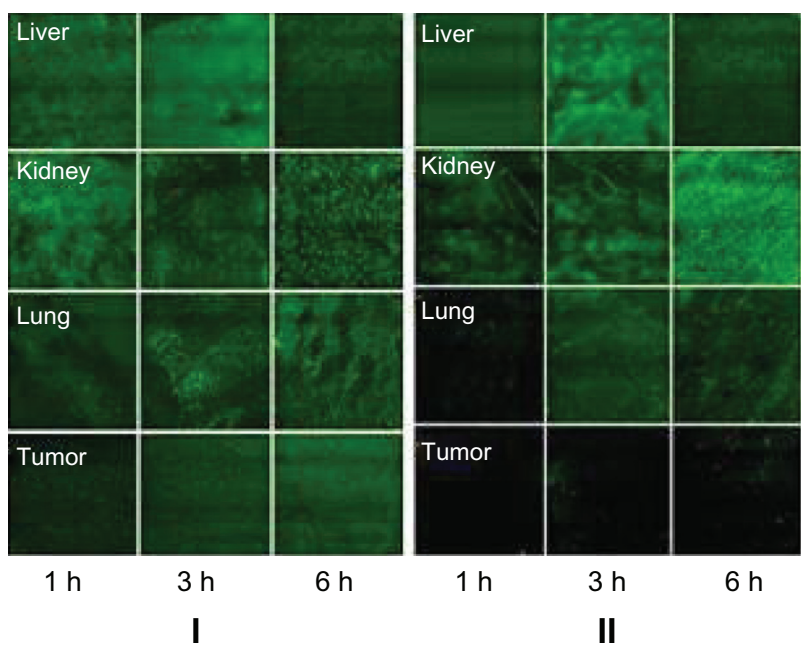

Figure 8 Distributions of PEI/ASON and NGR/PEI/ASON complexes in BALB/C nude mice after injection from I to 6 hours. I: Group (injection with NGR/PEI/ ASON complexes via tail vein), II: Group 2 (injection with PEI/ASON complexes via tail vein). Organs from top to bottom were liver, kidney, lung, and tumor. All samples were observed by confocal fluorescence microscopy.

Abbreviations: PEI, polyethylenimine; ASON, antisense oligonucleotide; NGR, asparagine-glycine-arginine peptide. its analog could be a useful component in delivery systems for cancer drugs.

\section{Acknowledgments}

This research was supported financially by the Natural Science Foundation of China and the National Center for Nanoscience and Technology.

\section{Disclosure}

The authors report no conflicts of interest in this work.

\section{References}

1. Gao Y, Xu Z, Chen S, Gu W, Chen L, Li Y. Arginine-chitosan/DNA self-assemble nanoparticles for gene delivery: in vitro characteristics and transfection efficiency. Int J Pharm. 2008;359:241-246.

2. Coppelli FM, Grandis JR. Oligonucleotides as anticancer agents: from the benchside to the clinic and beyond. Curr Pharm Des. 2005;11: 2825-2840.

3. Piro LD. Apoptosis, Bcl-2 antisense, and cancer therapy. Oncology (Williston Park). 2004;18(13 Suppl 10):5-10.

4. Kraemer K, Schmidt U, Fuessel S, Herr A, Wirth MP, Meye A. Microarray analyses in bladder cancer cells: inhibition of hTERT expression down-regulates EGFR. Int J Cancer. 2006;119:1276-1284.

5. Skod C, Erovic BM, Wachek V, et al. Down-regulation of Mcl-1 with antisense technology alters the effect of various cytotoxic agents used in treatment of squamous cell carcinoma of the head and neck. Oncol Rep. 2008;19:1499-1503.

6. Gewirtz AM, Sokol DL, Ratajczak MZ. Nucleic acid therapeutics: State of the art and future prospects. Blood. 1998;92:712-736.

7. Tripathy SK, Black HB, Goldwasser E, Leiden JM. Immune responses to transgene-encoded proteins limit the stability of gene expression after injection of replication-defective adenovirus vectors. Nat Med. 1996;2:545-550

8. Junghans M, Kreuter J, Zimmer A. Antisense delivery using protamineoligonucleotide particles. Nucleic Acids Res. 2000;28:E45.

9. Ewert KK, Ahmad A, Bouxsein NF, Evans HM, Safinya CR. Non-viral gene delivery with cationic liposome-DNA complexes. Methods Mol Biol. 2008;433:159-175.

10. Chumakova OV, Liopo AV, Andreev VG, et al. Composition of PLGA and PEI/DNA nanoparticles improves ultrasound-mediated gene delivery in solid tumors in vivo. Cancer Lett. 2008;261:215-225.

11. Garde SV, Forte AJ, Ge M, et al. Binding and internalization of NGRpeptide-targeted liposomal doxorubicin (TVT-DOX) in CD13-expressing cells and its antitumor effects. Anticancer Drugs. 2007;18:1189-1200. 
12. Cho K, Ishiwata T, Uchida E, et al. Enhanced expression of keratinocyte growth factor and its receptor correlates with venous invasion in pancreatic cancer. Am J Pathol. 2007;170:1964-1974.

13. van Laarhoven HW, Gambarota G, Heerschap A, et al. Effects of the tumor vasculature targeting agent NGR-TNF on the tumor microenvironment in murine lymphomas. Invest New Drugs. 2006;24:27-36.

14. Curnis F, Arrigoni G, Sacchi A, et al. Differential binding of drugs containing the NGR motif to CD13 isoforms in tumor vessels, epithelia, and myeloid cells. Cancer Res. 2002;62:867-874.
15. Romoren K, Pedersen S, Smistad G, Evensen O, Thu BJ. The influence of formulation variables on in vitro transfection efficiency and physicochemical properties of chitosan-based polyplexes. Int J Pharm. 2003; 261:115-127.

16. Sharma VK, Thomas M, Klibanov AM. Mechanistic studies on aggregation of polyethylenimine-DNA complexes and its prevention. Biotechnol Bioeng. 2005;90:614-620.

\section{Publish your work in this journal}

The International Journal of Nanomedicine is an international, peerreviewed journal focusing on the application of nanotechnology in diagnostics, therapeutics, and drug delivery systems throughout the biomedical field. This journal is indexed on PubMed Central, MedLine, CAS, SciSearch ${ }^{\circledR}$, Current Contents ${ } /$ Clinical Medicine, Journal
Citation Reports/Science Edition, EMBase, Scopus and the Elsevier Bibliographic databases. The manuscript management system is completely online and includes a very quick and fair peer-review system, which is all easy to use. Visit http://www.dovepress.com/ testimonials.php to read real quotes from published authors. 